\title{
COMMENTARY
}

\section{Comparison Can Be a Basis For Resilience Rather Than the Thief of Joy}

\author{
Zara Risoldi-Cochrane, PharmD, ${ }^{\mathrm{a}}$ Timothy J. Bloom, $\mathrm{PhD}^{\mathrm{a}, \mathrm{b}}$ \\ ${ }^{a}$ Shenandoah University, Bernard J. Dunn School of Pharmacy, Winchester, Virginia \\ ${ }^{\mathrm{b}}$ Editorial Board Member, American Journal of Pharmaceutical Education, Arlington, Virginia
}

Corresponding Author: Timothy J. Bloom, Shenandoah University, Bernard J Dunn School of Pharmacy, 1775 N. Sector Ct., Winchester, VA 22601. Tel: 540-678-4395. Email: tbloom2@su.edu

Submitted February 26, 2021; accepted June 20, 2021; ePublished July 2021

Keywords: wellness, self-care, faculty development, student support

Each of us knows that life involves challenges, and times that are difficult to get through. It can be argued that getting through those difficulties makes us stronger, and more resilient to future difficulties that inevitably lie ahead. While getting through difficult times, we learn new strategies for success, new problem solving skills, or even just that we are stronger and more durable than we may have thought. Over the past year and more, we have all been living with massive disruptions of our lives - personal, professional and educational. When living through a challenge becomes the marathon we have all been experiencing since early 2020, it is reasonable to feel put upon by the universe. Being angry, sad, frightened, exhausted and anxious are all completely normal and indeed reasonable responses to what we have been going through. Accepting that life involves ups and downs does not mean we are ready for such long-lasting stress. Despite everything that is going on, people still must earn a living and take care of their family, children still must learn how to take their place in the world, and the cooperation required for a successful human society still must continue.

In the face of life-disrupting events, there are some people who handle difficulty better and seem less disrupted on a day-to-day basis. There are several possible explanations for this resilience. They may have gone through something similar already, and as a result are more confident that they will get through a new challenge. There have been reports that older folk tend to be maintaining their spirits during the pandemic better than those who are younger, perhaps in part due to more life experience and thus more chances to have practiced overcoming challenges. ${ }^{1}$ Some people also may be inherently more positive in their outlook on life, and therefore be harder to throw off kilter when things go wrong. We all know someone who somehow keeps a bright outlook despite whatever is going on around them. Depending on our own personality, these people may help us feel more positive as well, or they may frustrate us with their "overly optimistic" outlook. Or the people who are less bothered by events around them may have developed skills they can use when facing a challenge, which helps them maintain a sense that things aren't quite that bad yet. We don't have control over how old and experienced we are, and except in limited circumstances can usually make only small changes in our basic personality and temperament. However, we can all learn skills related to how we think about a situation and direct the reaction we have to what is happening.

Two studies of satisfaction in Olympic medalists examine one of these skills: counterfactual thinking, or the comparison of actual events to what could have happened. Both studies examined the initial responses of medal winners to determine how satisfied they were with the outcome of their event. Although gold medalists were the most satisfied as a group, the bronze medalists were determined to be more satisfied than the silver medalists. The reason for a gold medal winner's satisfaction is clear- they had demonstrated they were the best in the world at their event. As expected, most silver medalists were less satisfied than gold medalists, but they were also less satisfied than bronze medalists. The authors speculated that this happened because the silver medalists were aware of how close they had come to first place, and therefore saw the outcome as a disappointment. On the other hand, bronze medalists tended to compare themselves to the competitors who did not make it to the podium, and saw themselves as having done well. The authors suggested that an important factor for medalist satisfaction was the comparison of the actual outcome to the most likely alternative. A suggestion of these studies is that our basis for comparison can help determine how we feel about our current situation. ${ }^{2,3}$

We as faculty are compared to standards set by our institution for a number of reasons: to measure our effectiveness as teachers and scholars, to determine whether we will be promoted or granted tenure, and so on. Although we may feel we do not have much control over the institutional systems within which we work, we do have some control over our reaction to those systems' outcomes. Perhaps we can learn from Olympic bronze medalists to help ourselves cope with life's difficulties, whether small or large, by using comparison. Comparison is often thought of as something 
negative - the proverbial thief of joy. In reality, comparison serves as a form of reflection: a self-evaluation of what is going well and what isn't, or where we are now versus where we need to be. This kind of reflection has been cited as a valuable way to foster resiliency in pharmacy students and residents. ${ }^{4-6}$ By demonstrating that reflection ourselves, we model for our students a skill they can use as they face their own challenges.

The comparisons we choose to make impact whether we perceive our outcomes as successes (to be celebrated and shared) or failures (to be derided and locked away). Earning a silver medal is an enormous achievement, to be sure, and the culmination of years of hard work, training, and personal growth. But if we only compare ourselves to the competitor who took home gold, we can only view this situation as a failure - as falling short of the goal or intended result.

We see this with students who enter pharmacy school and underestimate the transition to a professional, graduatelevel degree program. As the authors meet with academic advisees, we ask them to set personal, professional, and academic goals for their first year. Several times, we've had students tell us they plan to get straight A's in pharmacy school, often despite the fact that they struggled to maintain a B average in their undergraduate coursework. Is this a realistic goal for these students? Of course, pharmacy faculty want to encourage each student's success and would never hold them back from reaching their full academic potential. But at the end of the semester, will these students feel they have failed if they see a B on their transcript? Would they be happier if they had set their sights on earning B's and C's, and met (or exceeded) this goal?

It's a good reminder to also set expectations for ourselves that are achievable. Just as we would write educational objectives that stretch the learner's abilities but are ultimately attainable, we should show ourselves the same consideration. Otherwise, we risk comparing ourselves and our work to ideals and standards of performance that we can never live up to, thereby setting ourselves up for a perception of failure. It seems intuitive that comparison can be a useful tool to help motivate ourselves to meet those standards. We compare what we need with what we have, and take steps to fill the gaps we identify. How do we then view the outcome of our work? Sometimes we are ecstatic to have met our goals, and other times we are upset by failing to hit the mark.

This is not meant to suggest that failure is always a negative experience. On the contrary, failure may have a powerful role in education and learning. Eskreis-Winkler and Fishbach review a body of research that demonstrates that negative experiences and information command our attention, are processed more deeply than positive information, and persist in our memories. ${ }^{7}$ Loscalzo argues that failure is imperative within medical education in order to develop students' and residents' tenacity and self-control. ${ }^{8}$ Sharing examples of our failures is one way we can demonstrate vulnerability and persistence to our students, fostering a learning environment where they can take intellectual risks. ${ }^{9}$

Yet teachers are less likely to share their professional failures with other teachers than they are professional successes. Across settings, individuals consistently undershare lessons learned from failed experiences, even when those failures objectively contain more useful information than successes. ${ }^{7}$ How do we combat this? If we can uncouple failure from shame and humiliation, we can begin to explore what we learned from these experiences. This is easier said than done, of course, but there are steps we can take to model this approach to our students, and to encourage a culture where failures are viewed as learning experiences, without fear of embarrassment or loss of status.

Years ago, one of the authors attended a teaching and learning conference where participants took turns sharing an "oops moment", describing a time when things had not gone as planned in the classroom. What began as a reluctant icebreaker activity, with individuals avoiding eye contact as they meekly shared an anecdote, soon turned into a rollicking conversation as stories grew more elaborate and we laughed together over common experiences. Perhaps

counterintuitively, giving voice to our "oops moments" took away the sting of failure, allowing us to see and share lessons that we learned from the experience. Hearing others' stories allowed us to compare our experiences, and see that we were not failures, but quite normal. We were also reminded that we had taken that experience of failure and used it to learn and grow as teachers.

The same strategy of intentional comparison can be applied in the learning environment. Let's not focus solely on the solution to problem-solving activities, but instead ask our students: What did you try that didn't work? Based on this experience, what would you do differently in the future? Let's not reserve praise for successful ventures only. Recognize the effort made and the insight gained from taking big swings in the classroom, regardless of the outcome. Let's ask our students to be mindful of the comparisons they are making, and invite them to show self-compassion when the results don't quite live up to their own expectations.

Ultimately, many stories about failure end up being stories of resilience, because we're still here, still moving forward, applying what we've learned and striving to be better with each passing day. If you can model that for your students, you'll deserve a gold medal indeed. 


\section{REFERENCES}

1. Czeisler, ME, Lane, RI, Petrosky, E, Wiley, JF, et al. Mental Health, Substance Use, and Suicidal Ideation During the COVID-19 Pandemic — United States, June 24-30, 2020. MMWR Morb Mortal Wkly Rep 2020;69:10491057. DOI: http://dx.doi.org/10.15585/mmwr.mm6932a1

2. Medvec, VH, Madey, SF, and Gilovich T. When less is more: counterfactual thinking and satisfaction among Olympic medalists. J Pers Soc Psychol. 1995;69(4):603-610 PMID: 7473022

3. Matsumoto, D and Willingham, B. The thrill of victory and the agony of defeat: spontaneous expressions of medal winners of the 2004 Athens Olympic Games. J Pers Soc Psychol. 2006;91(3):568-581

4. Kang K, Ortiz Lopez CF, Fear BS, Granko RP. Tactics to improve resilience and well-being among pharmacy students. Am J Health-Syst Pharm. 2019;76(18):1374-1376. doi:10.1093/ajhp/zxz143

5. Swanson S, Schweiss S. Resident perceptions of a resilience curriculum in a postgraduate year 1 (PGY1) pharmacy residency program. Curr Pharm Teach Learn. 2019;11(9):949-955. doi:10.1016/j.cptl.2019.05.004

6. Finley RS. Reflection, resilience, relationships, and gratitude. Am J Health-Syst Pharm. 2018;75:1185-1190. doi:10.2146/ajhp180249

7. Eskreis-Winkler, L, and Fishbach, A. Hidden failures. Organ Behav Hum Decis Process. 2020;157:57-67. doi:10.1016/j.obhdp.2019.11.007

8. Loscalzo, JA. A Celebration of Failure. Circ. 2014;129(9):953-955.

9. Ramirez, A. Making friends with failure. Edutopia. August 26, 2013. Accessed February 21, 2021. https://www.edutopia.org/blog/learning-from-failure-ainissa-ramirez 